\title{
Desempenho de cordeiros em confinamento alimentados com dieta exclusiva de concentrado com diferentes porcentagens de proteína
}

\author{
[Performance of feedlot lambs feed with exclusive concentrate diet \\ with different percentages of protein] \\ L.G.A.Cirne ${ }^{1}$, G.J.C. Oliveira ${ }^{2}$, S.M.P.L. Jaeger ${ }^{2}$, A.R. Bagaldo ${ }^{2}$, M.C.P. Leite ${ }^{2}$, \\ P.A. Oliveira ${ }^{3}$ C.M. Macedo Junior ${ }^{4}$ \\ ${ }^{1}$ Aluno de pós-graduação - UNESP/FCAV - Jaboticabal, SP \\ ${ }^{2}$ Universidade Federal do Recôncavo Baiano - Cruz das Almas, BA \\ ${ }^{3}$ Aluno de pós-graduação - Universidade Federal do Recôncavo Baiano - Cruz das Almas, BA \\ ${ }^{4}$ Aluno de graduação - Universidade Federal do Recôncavo Baiano - Cruz das Almas, BA
}

\begin{abstract}
RESUMO
O presente experimento foi realizado com o objetivo de avaliar o desempenho de cordeiros em confinamento alimentados com dieta exclusiva de concentrado com diferentes porcentagens de proteína. Foram utilizados 24 cordeiros mestiços da raça Santa Inês, não castrados, com aproximadamente 180 dias de idade, peso vivo médio de $25 \mathrm{~kg}$, confinados, num delineamento experimental inteiramente ao acaso, com quatro tratamentos e seis repetições. O consumo voluntário de matéria seca, matéria orgânica, proteína bruta e nutrientes digestíveis totais, além do ganho de peso diário e total, da conversão e da eficiência alimentar dos cordeiros, não foram influenciados $(\mathrm{P}>0,05)$ pela porcentagem de proteína na dieta. As dietas com 18 e $20 \%$ de proteína bruta apresentaram menores custos de produção, entretanto o menor custo foi obtido com a ração contendo $18 \%$ de PB.
\end{abstract}

Palavras-chave: cordeiro, consumo, ganho de peso, proteína

\begin{abstract}
The experiment was conducted to evaluate the performance of feedlot lambs feed with exclusive concentrate diet with different percentages of protein. A total of twenty four confined, not castrated Santa Inês crossbred lambs, with approximately 180 days of age, average live weight of $25 \mathrm{~kg}$, in a completely randomized design, with four treatments and six repetitions were used. Voluntary intake of dry matter, organic matter, crude protein and total digestible nutrient, besides the daily and total gains, conversion and feed efficiency of feedlot lambs were not affected $(P>0.05)$ by percentage of dietary crude protein. Diets with 18 and $20 \%$ crude protein had lower production costs, however, the lowest cost was obtained with a diet containing $18 \% \mathrm{CP}$.
\end{abstract}

Keywords: lamb, intake, weight gain, protein

\section{INTRODUÇÃO}

Dietas de alto concentrado, classificadas como $100 \%$ grão, contendo $85 \%$ de grão de milho inteiro mais $15 \%$ de um pélete proteico complementar, estão sendo usadas em alguns confinamentos como fonte exclusiva de alimentos. Segundo Preston (1998), essa prática caracteriza-se por rápido ganho de peso, alta eficiência alimentar e consequente redução no tempo para terminação e abate e maior uniformidade do produto final.

No Brasil, dietas para confinamento, tradicionalmente, são balanceadas com altas proporções de volumosos, devido aos altos custos dos grãos e dos concentrados proteicos.

Recebido em 3 de abril de 2012

Aceito em 28 de agosto de 2012

E-mail: lgabrielcirne@hotmail.com 
Entretanto, quando os grãos apresentam preços vantajosos, dietas com altas porcentagens de concentrado tornam-se viáveis economicamente, pois reduzem os custos com mão de obra e tornam a atividade mais rentável (Bulle et al., 1999).

O fornecimento de dietas com elevados teores de concentrado para animais jovens, que apresentam boas respostas a esse tipo de alimentação, tem sido utilizado com o objetivo de intensificar o sistema de produção, pois permite o abate de animais dessa categoria com acabamento de gordura adequado, sem prejuízos à qualidade da carne (Leme et al., 2002).

De acordo com Mendes et al. (2010), em dietas com alta proporção de ingredientes concentrados, é mais seguro o uso de um teor mínimo de fibra capaz de estimular a mastigação e permitir ambiente ruminal adequado para não prejudicar o desempenho animal. Sobrinho et al. (1996), ao analisarem o fornecimento de grãos inteiros para cordeiros em confinamento, observaram diminuição do ritmo de fermentação ruminal e aumento do tempo de ruminação e de ingestão, elevando a secreção de saliva e o $\mathrm{pH}$ do rúmen. Verificaram também que o fornecimento de grãos inteiros não causou prejuízos à digestibilidade nem à conversão alimentar.

Objetivou-se com o presente trabalho avaliar o desempenho de cordeiros em confinamento alimentados com dieta exclusiva de concentrado e diferentes porcentagens de proteína.

\section{MATERIAL E MÉTODOS}

Foram utilizados 24 cordeiros mestiços da raça Santa Inês, não castrados, com 180 dias de idade, peso vivo médio de $25 \mathrm{~kg}$, confinados, distribuídos em baias individuais de $1 \mathrm{~m}^{2}$, contendo comedouro, saleiro e bebedouro. O experimento teve duração de 38 dias, sendo oito dias para adaptação e 30 dias para coleta de dados. As dietas foram compostas por grãos de milho, farelo de soja, sal mineral e água à vontade. Todos os animais receberam vitamina ADE como suplemento vitamínico no início do experimento.

Os tratamentos foram constituídos de dietas com $14,16,18$ e $20 \%$ de proteína bruta, todas isoenergéticas, com $82 \%$ de nutrientes digestíveis totais (Tab. 1). A dieta oferecida correspondeu a $4 \%$ do PV, e os animais passaram por um período de adaptação de oito dias, com oferta de $1 ; 1,5 ; 2$ e $4 \%$ do peso vivo dos animais no primeiro, terceiro, quinto $\mathrm{e}$ sétimo dias, respectivamente. Os animais foram alimentados três vezes ao dia, às seis, 14 e 22 horas, e as sobras diárias das dietas foram recolhidas, pesadas e subtraídas do total fornecido, a fim de quantificar o material consumido pelos animais individualmente.

Tabela 1. Proporção dos alimentos e ingredientes com base na matéria seca das dietas utilizadas na alimentação de cordeiros em confinamento

\begin{tabular}{lcccc}
\hline \multirow{2}{*}{ Item } & \multicolumn{4}{c}{ Porcentagem de proteína bruta } \\
\cline { 2 - 5 } Milho grão & 14 & 16 & 18 & 20 \\
Farelo de soja & 86,49 & 81,08 & 75,68 & 70,27 \\
\hline & 13,51 & 18,92 & 24,32 & 29,73 \\
\hline Matéria seca & \multicolumn{4}{c}{ Nutrientes (\% MS) } \\
Proteína bruta & 88,00 & 88,00 & 88,00 & 88,00 \\
Nutrientes digestíveis totais & 14,00 & 16,00 & 18,00 & 20,00 \\
Extrato etéreo & 82,00 & 82,00 & 82,00 & 82,00 \\
Fibra em detergente neutro & 4,32 & 4,18 & 4,05 & 3,91 \\
Fibra em detergente ácido & 13,67 & 13,59 & 13,49 & 13,40 \\
Cinzas & 6,32 & 6,56 & 6,74 & 6,95 \\
Carboidratos não fibrosos & 2,39 & 2,67 & 2,94 & 3,22 \\
\hline
\end{tabular}

As características avaliadas foram o consumo voluntário de matéria seca (MS), matéria orgânica (MO), proteína bruta (PB) e nutrientes digestíveis totais (NDT), além do peso vivo inicial (PVI), peso vivo final (PVF), ganho de peso diário (GPD), ganho de peso total (GPT), 
conversão alimentar (CA), eficiência alimentar (EA) e análise econômica.

O delineamento experimental utilizado foi o inteiramente ao acaso, com quatro tratamentos e seis repetições, totalizando 24 unidades experimentais. Os dados foram submetidos a análises de variância e de regressão, assumindo o nível de 5\%, e utilizou-se o programa estatístico SAS.

\section{RESULTADOS E DISCUSSÃO}

O consumo voluntário de MS, MO, PB e NDT não foi afetado $(\mathrm{P}>0,05)$ pelas porcentagens de proteína bruta na dieta (Tab. 2).

Tabela 2. Médias de consumo voluntário de matéria seca, matéria orgânica, proteína bruta e nutrientes digestíveis totais por cordeiros alimentados com dieta exclusiva de concentrado e diferentes porcentagens de proteína bruta

\begin{tabular}{lcccccc}
\hline \multirow{2}{*}{ Consumo } & \multicolumn{3}{c}{ Porcentagem de } & proteína bruta & \multirow{2}{*}{ Média } & \multirow{2}{*}{ CV $(\%)$} \\
\cline { 2 - 5 } & 14 & 16 & 18 & 20 & & \\
\hline Matéria seca (kg/dia) & 1,041 & 0,935 & 1,044 & 0,989 & 1,002 & 12,82 \\
Matéria orgânica (kg/dia) & 1,016 & 0,910 & 1,012 & 0,956 & 0,974 & 12,69 \\
Proteína bruta (kg/dia) & 0,160 & 0,170 & 0,219 & 0,236 & 0,196 & 20,38 \\
Nutrientes digestíveis totais (kg/dia) & 0,860 & 0,768 & 0,851 & 0,802 & 0,820 & 12,91 \\
\hline
\end{tabular}

O consumo médio de matéria seca, de $1,005 \mathrm{~kg} / \mathrm{dia}$, foi semelhante ao encontrado por Fluharty et al. (1999), de $1,053 \mathrm{~kg} / \mathrm{dia}$, com cordeiros Targhee, em confinamento, alimentados com dietas exclusivas de concentrado, e por Rocha et al. (2004), de $1,060 \mathrm{~kg} / \mathrm{dia}$, com cordeiros Santa Inês, em confinamento, arraçoados com dietas contendo $80 \%$ de concentrado; e mais baixo que o observado por Murphy et al. (1994a), de $1,350 \mathrm{~kg} / \mathrm{dia}$, com animais $1 / 2$ Hampshire $\mathrm{x} 1 / 2$ Targhee, em confinamento, alimentados com dietas exclusivas de concentrado. A ingestão média de MS observada, neste estudo, está na faixa preconizada pelo NRC (National..., 1985), que é de 1.000 e $1.300 \mathrm{~g} / \mathrm{dia}$ para cordeiros com peso vivo médio de 20 e $30 \mathrm{~kg}$, respectivamente. O consumo de MS é importante no desempenho de ovinos em confinamento e pode ser considerado determinante do aporte de nutrientes necessários para o atendimento das exigências de mantença e de ganho de peso dos animais (Sniffen et al., 1993).

Mesmo não apresentando diferença significativa $(\mathrm{P}>0,05)$ para a ingestão de $\mathrm{PB}$, com valor médio de $0,196 \mathrm{~kg} / \mathrm{dia}$, houve aumento no consumo desse nutriente, sendo o maior consumo atribuído à elevação dos níveis de $\mathrm{PB}$ dos tratamentos. No entanto, a ingestão média de PB (0,196kg/dia) está de acordo com a recomendação do NRC (National..., 1985), de 167 e $191 \mathrm{~g} \mathrm{~PB} /$ dia para cordeiros de 20 e $30 \mathrm{~kg}$ $\mathrm{PV}$, respectivamente. Da mesma forma, o consumo médio de NDT, de $0,822 \mathrm{~kg} / \mathrm{dia}$, está próximo dos valores recomendados pelo NRC (National..., 1985) para animal em crescimento moderado, de 0,800 e $1,00 \mathrm{~kg}$ NDT/dia para cordeiros de 20 e $30 \mathrm{~kg} \mathrm{PV}$, respectivamente.

O PVI, o PVF, o GPD, o GPT, a CA e a EA dos cordeiros em confinamento não foram influenciados $(\mathrm{P}>0,05)$ pelas porcentagens de proteína bruta na dieta (Tab. 3).

O GPD médio, de $0,301 \mathrm{~kg} / \mathrm{dia}$, foi inferior ao observado por Murphy et al. (1994a) e por Jacques et al. (2011), de 0,407 e 0,449kg/dia, com animais $1 / 2$ Hampshire $\mathrm{x} \quad 1 / 2$ Targhee $\mathrm{e}$ Dorset, em confinamento, com dietas exclusivas de concentrado, respectivamente, sendo importante ressaltar a composição genética desses animais, pois raças especializadas na produção de carne, como Hampshire e Dorset, apresentam elevadas taxas de ganhos de peso, semelhantes às registradas por Murphy et al. (1994b) e Fluharty et al. (1999), de 0,316 e $0,291 \mathrm{~kg} / \mathrm{dia}$, respectivamente, em cordeiros em confinamento, alimentados com dietas exclusivas de concentrado, e superiores ao encontrado por Rocha et al. (2004), de 0,227kg/dia, em cordeiros em confinamento, alimentados com dietas contendo $80 \%$ de concentrado com diferentes porcentagens de proteína bruta, o que sugere que dietas exclusivas de concentrado sejam uma alternativa na terminação de cordeiros em confinamento. 
Tabela 3. Médias do peso vivo inicial, peso vivo final, ganho de peso diário, ganho de peso total, conversão alimentar e eficiência alimentar de cordeiros alimentados com dieta exclusiva de concentrado e diferentes porcentagens de proteína bruta

\begin{tabular}{|c|c|c|c|c|c|c|}
\hline \multirow{2}{*}{ Item } & \multicolumn{4}{|c|}{ Porcentagem de proteína bruta } & \multirow{2}{*}{ Média } & \multirow{2}{*}{$\mathrm{CV}(\%)$} \\
\hline & 14 & 16 & 18 & 20 & & \\
\hline Peso vivo inicial (kg) & 25,46 & 22,84 & 24,60 & 23,56 & 24,12 & 8,97 \\
\hline Peso vivo final $(\mathrm{kg})$ & 33,70 & 30,32 & 33,36 & 32,66 & 32,51 & 8,57 \\
\hline Ganho de peso diário $(\mathrm{kg})$ & 0,283 & 0,258 & 0,342 & 0,313 & 0,300 & 25,76 \\
\hline Ganho de peso total $(\mathrm{kg})$ & 8,23 & 7,48 & 9,93 & 9,10 & 8,69 & 25,73 \\
\hline Conversão alimentar (kg MS/kg PV) & 3,51 & 3,62 & 3,23 & 3,08 & 3,36 & 15,76 \\
\hline Eficiência alimentar (kg PV/kg MS) & 0,259 & 0,262 & 0,314 & 0,307 & 0,285 & 16,14 \\
\hline
\end{tabular}

A CA de 3,35 foi similar à observada por Murphy et al. (1994a), com CA de 3,32, próxima à observada por Fluharty et al. (1999) e Jacques et al. (2011), com CA de 3,59 e 3,44, respectivamente, em cordeiros alimentados com dietas exclusivas de concentrado. A baixa CA registrada neste trabalho pode ser atribuída à dieta exclusiva de concentrado, a qual apresenta alta densidade energética. Segundo Mertens (1994), em ração com baixa concentração de fibras em relação às exigências do animal, o consumo será limitado pela demanda energética do animal, que poderá deixar de ingerir alimentos, mesmo que o rúmen não esteja repleto.

Os custos das dietas, em $\mathrm{R} \$ / \mathrm{kg}$ de $\mathrm{MS}$, elevaramse à medida que se aumentaram as porcentagens de PB nelas (Tab. 4). Porém, com o aumento das porcentagens de $\mathrm{PB}$ nas rações, os animais apresentaram melhor conversão alimentar, o que refletiu no custo por ganho em $\mathrm{kg}$ de peso vivo (PV), pois as dietas com 18 e $20 \%$ de PB proporcionaram menores custos na terminação de cordeiros em confinamento alimentados com dieta exclusiva de concentrado.

Tabela 4. Viabilidade econômica das diferentes porcentagens de proteína bruta em dieta exclusiva de concentrado para cordeiros em confinamento

\begin{tabular}{lcccc}
\hline & \multicolumn{3}{c}{ Porcentagem de proteína bruta } \\
\cline { 2 - 5 } & 14 & 16 & 18 & 20 \\
\hline Custo do concentrado $(\mathrm{R} \$ / \mathrm{kg})^{1}$ & 0,49 & 0,50 & 0,53 & 0,54 \\
Custo do sal mineral $(\mathrm{R} \$ / \mathrm{kg})$ & 1,13 & 1,13 & 1,13 & 1,13 \\
Ingestão do concentrado $(\mathrm{kg})$ & 36,30 & 31,86 & 35,58 & 33,72 \\
Ingestão de sal mineral $(\mathrm{kg})$ & 1,92 & 2,29 & 1,99 & 2,34 \\
Custo alimento/cordeiro & 19,96 & 18,52 & 21,11 & 20,85 \\
Custo/ganho (kg de PV) R\$ & 2,43 & 2,48 & 2,13 & 2,29 \\
\hline
\end{tabular}

\section{CONCLUSÕES}

Dieta exclusiva de concentrado com até $20 \%$ de proteína bruta não afeta o desempenho de cordeiros em confinamento. A porcentagem de $18 \%$ de proteína bruta na ração apresentou menor custo de produção, entretanto a utilização de dieta exclusiva de concentrado depende de fatores econômicos e da disponibilidade dos ingredientes em cada região.

\section{REFERÊNCIAS}

BULLE, M.L.M.; RIBEIRO, F.G.; LEME, P.R. et al. Uso do bagaço de cana-de-açúcar como único volumoso em dietas de alto teor de concentrado. 1. Desempenho. In: REUNIÃO ANUAL DA SOCIEDADE BRASILEIRA DE ZOOTECNIA, 36., 1999, Porto Alegre. Anais... Porto Alegre: [s.n.] 1999. (Resumo).

FLUHARTY, F.L.; McCLURE, K.E.; SOLOMON, M.B. et al. Energy source and Ionophore supplementation effects on lamb growth, carcass characteristics, visceral organ mass, diet digestibility, and nitrogen metabolism. J. Anim. Sci., v.77, p.816823, 1999. 
JACQUES, J.; BERTHIAUME, R.; CINQ-MARS, D. Growth performance and carcass characteristics of Dorset lambs fed different concentrates: Forage ratios or fresh grass, Small Rum. Res., v.95, p.113-119, 2011.

LEME, P.R.; SILVA, S.L.; PEREIRA, A.S.C. et al. Desempenho e características de carcaça de animais Nelore, 1/2 Caracu x Nelore e 3/4 Caracu x Nelore confinados com dietas de alto concentrado. In: REUNIÃO ANUAL DA SOCIEDADE BRASILEIRA DE ZOOTECNIA, 39., 2002, Recife. Anais... Recife: [s.n.] 2002. (Resumo).

MENDES, C.Q.; TURINO, V.F.; SUSIN, I. et al. Comportamento ingestivo de cordeiros $\mathrm{e}$ digestibilidade dos nutrientes de dietas contendo alta proporção de concentrado e diferentes fontes de fibra em detergente neutro. Rev. Bras. Zootec., v.39, p.594-600, 2010.

MERTENS, D.R. Regulation of forage intake. In: NATIONAL CONFERENCE ON FORAGE QUALITY. EVALUATION AND UTILIZATION, 1994. Proceedings... Lincoln: [s.n.] 1994. p.450-493. (Resumo).

MURPHY, T.A.; LOERCH, S.C.; McCLURE, K.E. et al. Effects of grain or pasture finishing systems on carcass composition and tissue accretion rates of lambs. J. Anim. Sci., v.72, p.3138-3144, 1994b.
MURPHY, T.A.; LOERCH, S.C.; McCLURE, K.E. et al. Effects of restricted feeding on growth performance and carcass composition of lambs. $J$. Anim. Sci., v.72, p.3131-3137, 1994a.

NATIONAL reserch concil - NRC. Nutrient requirements of sheeps. Washington: National Academy Press, 1985. 99p.

PRESTON, R.L. Management of high concentrate diets in feedlot. In: SIMPÓSIO SOBRE PRODUÇÃO INTENSIVA DE GADO DE CORTE, 1998., Campinas. Anais... Campinas: [s.n] 1998. p.82-91. (Resumo).

ROCHA, M.H.M.; SUSIN, I.; PIRES, A.V. et al. performance of Santa Inês lambs fed diets of variable crude protein levels. Sci. Agric., v.61, p.141-145, 2004.

SNIFFEN, C.; BEVERLY, R.W.; MOONEY, C.S. et al. Nutrient requirement versus supply in dairy cow: strategies to account for variability. J. Dairy Sci., v.76, p.3160-3178, 1993.

SOBRINHO, A.G.S.; BATISTA, A.M.V.; SIQUEIRA, E.D. et al. (Ed). Nutrição de ovinos. Jaboticabal: FUNEP, 1996. 258p. 